\title{
Risiko Penularan HIV/AIDS pada Pekerja Seks Komersial (PSK) di Provinsi Gorontalo.
}

\author{
${ }^{1}$ Irwan ${ }^{2}$ Ramly Abudi \\ 1,2 Program studi Kesehatan Masyarakat Universitas Negeri Gorontalo \\ irwandel@yahoo.com
}

\begin{abstract}
Abstrak
Pengidap HIV/AIDS dan penderita AIDS sebagian besar masih berusia produktif. Menurut perhitungan kalau penderita berumur 25-29 tahun, sedangkan masa inkubasi sejak terjangkitnya HIV positif sampai AIDS positif adalah 5-10 tahun dapat diduga bahwa mereka tertular HIV sejak berumur 15-20 tahun (Padang, 2005). Tujuan penelitian untuk mengetahui gambaran tingkat pengetahuan PSK terhadap HIV/AIDS di Provinsi Gorontalo.

Jenis penelitian yang digunakan adalah bersifat deskriptif analitik, sampel terdiri atas 53 orang yang bekerja sebagai PSK di wilayah Provinsi Gorontalo. Hasil penelitian ini diperoleh bahwa pengetahuan Pekerja Seks Komersial (PSK) terhadap penyakit HIV/AIDS dari 162 responden diperoleh 96 orang (59.25\%) dikategorikan cukup, 38 orang $(23.45 \%)$ berpengetahuan baik dan 28 orang (17.30\%) diketahui berpengetahuan kurang.

Kata kunci : PSK dan tingkat pengetahuan
\end{abstract}

\begin{abstract}
People with HIV/AIDS and the majority of people with AIDS was productive. According to calculations if sufferers aged 25-29 years, whereas incubation period since HIV-positive terjangkitnya to AIDS positive was 5-10 years can be presumed that they are infected with HIV since she was 15-20 year (Pasture, 2005 The purpose of the research to know the description of the level of knowledge of commercial sex workers against HIV/AIDS in Gorontalo Province.

This type of research is descriptive analytic in nature, the sample consists of 53 people who work as kommercial sex workers in the province of Gorontalo. The results of this research were obtained that knowledge of commercial sex workers (PSK) to disease HIV/AIDS of the 162 respondents obtained 96 people $(59.25 \%)$ are categorized pretty, 38 people $(23.45 \%)$ both knowledgeable and 28 people $(17.30 \%)$ known to be knowledgeable less.
\end{abstract}

keyword: PSK and level of knowledge 


\section{Pendahuluan}

Pekerja Seks Komersial (PSK) merupakan golongan masyarakat yang mempunyai resiko yang cukup rawan terhadap penyakit AIDS. Pada usia dini, Pekerja Seks Komersial (PSK) sedang mencari identitas dirinya dalam pergaulan sehingga sangat mudah terpengaruh terhadap kebudayaan luar yang sering menimbulkan masalah-masalah sosial, seperti penyalahgunaan narkotika (obat terlarang), pergaulan bebas dan budaya permissive (budaya serba boleh), sedangkan informasi/ pengetahuan yang mereka terima mengenai akibat pergaulan bebas masih sangat rendah (Rahmat, 1997).

Pengidap HIV/AIDS dan penderita AIDS sebagian besar masih berusia produktif. Menurut perhitungan kalau penderita berumur 25-29 tahun, sedangkan masa inkubasi sejak terjangkitnya HIV positif sampai AIDS positif adalah 5-10 tahun dapat diduga bahwa mereka tertular HIV sejak berumur 15-20 tahun (Padang, 2005).

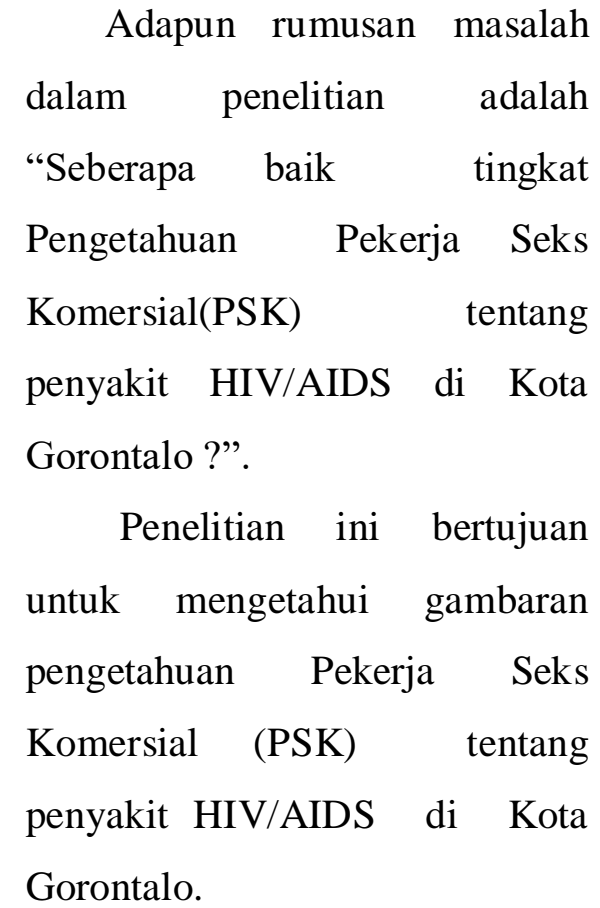

\section{METODE PENELITIAN}

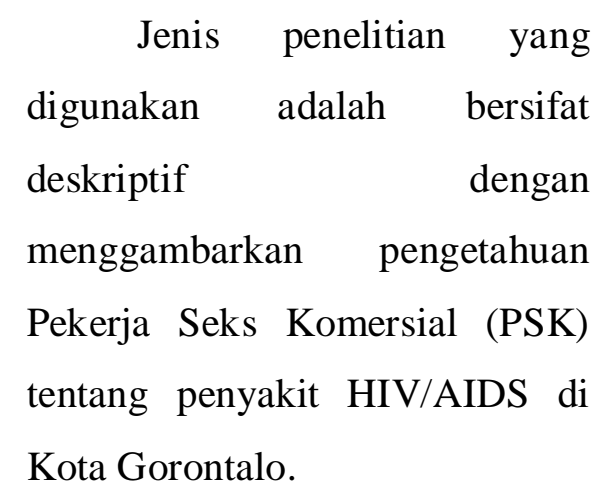

\section{Variabel Penelitian}

Penelitian ini menggunakan variabel mandiri yaitu pengetahuan Pekerja Seks Komersial (PSK) di Kota Gorontalo tentang penyakit HIV/AIDS. 
Populasi penelitian adalah Pekerja Seks Komersial (PSK) di Kota Gorontalo, yang tercatat pada Dinas Sosial Provinsi Gorontalo berjumlah 53 Orang.

Sementara Sampel penelitian adalah Seluruh Pekerja Seks Komersial (PSK) di Kota Gorontalo yang tercatat pada Dinas Sosial Provinsi Gorontalo sebanyak 53 orang. (Total sampling)

\section{HASIL PENELITIAN}

\section{Gambaran Umum Responden}

Tabel 1. Distribusi Responden Menurut Kelompok Umur Di Kota GorontaloTahun 2017

\begin{tabular}{|c|l|c|c|}
\hline No & $\begin{array}{c}\text { Kelompok } \\
\text { Umur }\end{array}$ & Jlh & $\%$ \\
\hline 1 & $17-21$ & 24 & 24 \\
\hline 2 & $21-29$ & 57 & 57 \\
\hline 3 & $30-35$ & 11 & 11 \\
\hline 4 & $>35$ & 8 & 8 \\
\hline & Total & 100 & 100 \\
\hline
\end{tabular}

Sumber : Data Primer

Berdasarkan data diatas terlihat bahwa umumnya responden berusia 21-29 Tahun sebanyak $57 \%$ responden yang berumur $17-21$ tahun sebanyak $24 \%$, resonden umur $>35$ tahun sebanyak $8 \%$.

Tabel 2. Distribusi responden berdasarkan daerah yang pernah dikunjungi sebelumnya Tahun 2017

\begin{tabular}{|c|l|c|c|}
\hline $\mathrm{N}$ & \multicolumn{1}{|c|}{$\begin{array}{c}\text { Tempat } \\
\text { tinggal } \\
\text { sebelumnya }\end{array}$} & Jlh & $\%$ \\
\hline 1 & Manado & 27 & 27 \\
\hline 3 & Makassar & 5 & 5 \\
\hline 4 & Surabaya & 9 & 9 \\
\hline 5 & Jakarta & 3 & 3 \\
\hline 6 & Gorontalo & 43 & 43 \\
\hline 7 & Lain-lain & 13 & 13 \\
\hline & Total & 100 & 100 \\
\hline
\end{tabular}

Sumber : Data Primer

Berdasarkan tabel diatas diketahui bahwa distribusi PSK sebelum datang ke Gorontalo pada umumya berasal dari Manado sebanyak $27 \%$, dari Kota Surabaya sebanyak $9 \%$. PSK yang tidak pernah keluar daerah selain diwilayah Provinsi Gorontalo sebanyak $43 \%$.

Tabel 3. Distribusi Pekerja Seks Komersial (PSK) Menurut Agama di Kota GorontaloTahun 2017

\begin{tabular}{|c|l|c|c|}
\hline No & Agama & $\begin{array}{c}\text { Jumla } \\
\text { h }\end{array}$ & $\%$ \\
\hline 1 & Islam & 89 & 89 \\
\hline 2 & $\begin{array}{l}\text { Kristen } \\
\text { Protestan }\end{array}$ & 7 & 7 \\
\hline 3 & $\begin{array}{l}\text { Kristen } \\
\text { Katolik }\end{array}$ & 14 & 14 \\
\hline & Total & 100 & 100 \\
\hline
\end{tabular}

Sumber Data Primer 
Dari data diatas terlihat bahwa pada umumnya responden beragama Islam sebanyak $89 \%$ responden yang beragama kiristen protestan sebanyak $7 \%$. Beragama Kristen katolik sebanyak $14 \%$.

Tabel 4. Distribusi Pengetahuan Responden tentang Penyakit IMS dan HIV/AIDS di Kota Gorontalo Tahun 2017

\begin{tabular}{|c|l|c|c|}
\hline No & Pengetahuan & Jlh & $\%$ \\
\hline 1 & Baik & 28 & 28 \\
\hline 2 & Cukup & 52 & 52 \\
\hline 3 & Kurang & 20 & 20 \\
\hline & Total & 100 & 100 \\
\hline
\end{tabular}

Sumber Data Primer

Dari tabel 4, dapat dilihat bahwa rata-rata responden pengetahuan cukup berjumlah 52 orang (52 \%) dan pengetahuan kurang berjumlah 20 orang (20\%).

Tabel 5. Distribusi Tingkat Pengetahuan Responden tentang Kondom di Kota Gorontalo Tahun 2017

\begin{tabular}{|c|c|c|c|}
\hline No & $\begin{array}{c}\text { Tingkat } \\
\text { Pengetahuan }\end{array}$ & Jlh & $\%$ \\
\hline 1 & Baik & 41 & 41 \\
2 & Cukup & 34 & 34 \\
3 & Kurang & 25 & 25 \\
\hline \multicolumn{2}{|c|}{ Jumlah } & $\mathbf{1 0 0}$ & $\mathbf{1 0 0}$ \\
\hline
\end{tabular}

Sumber : Data Primer

Berdasarkan Tabel 5 di atas, pengetahuan responden tentang kondom di Kota Gorontalo adalah 41 orang (41\%) baik, 34 orang (34\%) cukup dan 25 Orang (25\%) Kurang.

Tabel 6. Distribusi Tingkat Pengetahuan Responden tentang Manfaat Kondom di Kota Gorontalo Tahun 2017

\begin{tabular}{|c|c|c|c|}
\hline No & $\begin{array}{c}\text { Tingkat } \\
\text { Pengetahuan }\end{array}$ & Jlh & $\%$ \\
\hline 1 & Baik & 45 & 45 \\
2 & Cukup & 42 & 42 \\
3 & Kurang & 13 & 13 \\
\hline \multicolumn{2}{|c|}{ Jumlah } & $\mathbf{5 0}$ & $\mathbf{1 0 0}$ \\
\hline
\end{tabular}

Sumber : Data Primer

Berdasarkan Tabel 6 di atas, pengetahuan responden di Kota Gorontalo tentang manfaat kondom adalah 45 orang (45\%) baik dan 42 orang (42\%) cukup dan terdapat 13 Orang (13\%) yang kurang.

Tabel 7. Distribusi Pengetahuan Responden tentang Berapa Kali Kondom dapat digunakan pada PSK di Kota GorontaloTahun 2017

\begin{tabular}{|l|l|c|c|}
\hline No & $\begin{array}{c}\text { Tingkat } \\
\text { Pengetahuan }\end{array}$ & Jlh & $\%$ \\
\hline 1 & Satu kali & 86 & 86 \\
2 & Dua Kali & 13 & 13 \\
3 & Lebih Dua & - & - \\
& Kali & 100 & 100 \\
\hline \multicolumn{2}{|l|}{ Jumlah } &
\end{tabular}

Sumber : Data Primer

Berdasarkan Tabel $\quad 7 \quad$ di atas, pengetahuan responden tentang beberapa kali kondom dapat 
digunakan adalah 86 orang (86\%) satu kali , 13 orang (13\%) dua kali..

Tabel 8. Distribusi Pengetahuan Responden tentang Tempat Memperoleh Kondom di Kota Gorontalo Tahun 2017

\begin{tabular}{|c|c|c|c|}
\hline No & $\begin{array}{c}\text { Tingkat } \\
\text { Pengetahuan }\end{array}$ & $\begin{array}{c}\text { Jumla } \\
\mathrm{h}\end{array}$ & $\%$ \\
\hline 1 & Warung & 22 & 22 \\
\hline 2 & $\begin{array}{l}\text { Tempat } \\
\text { Hiburan/Kar } \\
\text { aoke }\end{array}$ & 67 & 67 \\
\hline 3 & Lain-lain & 11 & 11 \\
\hline \multicolumn{2}{|r|}{ Jumlah } & 50 & 100 \\
\hline
\end{tabular}

Sumber : Data Primer

Berdasarkan Tabel 8 di atas, pengetahuan responden tentang cara mendapatkan kondom adalah 22 orang (22\%) di warung, 67 orang (67\%) di tempat hiburan atau karaoke dan 11 Orang (11\%) ditempat lain-lain.

\begin{tabular}{|c|c|c|c|}
\hline $\begin{array}{l}\text { Res } \\
\text { Mer } \\
\text { Gor }\end{array}$ & $\begin{array}{lr}\text { 9. } & \text { Distrib } \\
\text { nden } & \text { ten } \\
\text { gunakan } & \text { Kon } \\
\text { italo Tahun } 20 \\
\end{array}$ & di & tida \\
\hline No & $\begin{array}{l}\text { Alasan Tidak } \\
\text { Menggunkaan } \\
\text { Kondom }\end{array}$ & $\mathrm{Jlh}$ & $\%$ \\
\hline 1 & $\begin{array}{l}\text { Keinginan } \\
\text { pasangan seks }\end{array}$ & 37 & 37 \\
\hline 2 & $\begin{array}{l}\text { Merasa tidak } \\
\text { nyaman }\end{array}$ & 58 & 58 \\
\hline 3 & Sulit diperoleh & 5 & \\
\hline & Jumlah & 100 & 1 \\
\hline
\end{tabular}

Sumber : Data Primer

Berdasarkan Tabel 9 di atas, alasan responden tidak menggunkan kondom adalah 37 orang (37\%) karena keinginan pasangan seks, 58 orang (58\%) karena merasa tidak nyaman dan 5 orang (5\%) karena sulit diperoleh.

Tabel 10. Distribusi Pengetahuan Responden tentang cara Penularan Penyakit HIV/AIDS di Kota Gorontalo Tahun 2017

\begin{tabular}{|c|c|c|c|}
\hline No & $\begin{array}{c}\text { Tingkat } \\
\text { Pengetahuan }\end{array}$ & Jlh & $\%$ \\
\hline 1 & Baik & 50 & 50 \\
2 & Cukup & 38 & 38 \\
3 & Kurang & 12 & 12 \\
\hline \multicolumn{2}{|c|}{ Jumlah } & 100 & 100 \\
\hline
\end{tabular}

Sumber : Data Primer

Berdasarkan Tabel 10 di atas, seluruh responden yaitu 50 orang $(50 \%)$ berpengetahuan baik tentang cara penularan Penyakit Menular Seksual (PMS) dan HIV / AIDS., terdapat 12 Orang (12\%) responden yang tidak mengetahui cara penularan penyakit HIV/AIDS

Tabel 11. Pengetahuan Responden Cara Mencegah IMS dan HIV / AIDS Di Kota Gorontalo Tahun 2017

\begin{tabular}{|c|c|c|c|}
\hline No & $\begin{array}{c}\text { Tingkat } \\
\text { Pengetahuan }\end{array}$ & Jlh & $\%$ \\
\hline 1 & Baik & 69 & 69 \\
2 & Cukup & 22 & 22 \\
3 & Kurang & 9 & 9 \\
\hline \multicolumn{2}{|c|}{ Jumlah } & 100 & 100 \\
\hline
\end{tabular}

Sumber : Data Primer 
Berdasarkan Tabel 11 di atas, pengetahuan responden di Kota Gorontalo tentang cara mencegah Penyakit Menular Seksual (IMS) dan HIV/ AIDS adalah 69 orang (69 \%) baik, 22 orang (22\%) cukup dan 9 orang ( $9 \%$ ) kurang.

Tabel 12. Distribusi Jenis /Merek Kondom yang digunakan oleh PSK di Kota Gorontalo Tahun 2017

\begin{tabular}{|c|c|c|c|}
\hline No & $\begin{array}{c}\text { Tingkat } \\
\text { Pengetahuan }\end{array}$ & Jlh & $\%$ \\
\hline 1 & Sutra & 11 & 11 \\
2 & Durex & 6 & 6 \\
3 & Artika & 78 & 78 \\
4 & Fiesta & 5 & 5 \\
\hline & Jumlah & 50 & 100 \\
\hline
\end{tabular}

Sumber : Data Primer

Berdasarkan Tabel 12 di atas, diketahui pada umumnya responden menggunkana jenis kondom Artika 78 Orang (78\%,) Kondom Durex 5 Orang (5\%)

\section{PEMBAHASAN}

Berdasarkan hasil penelitian yang dilakukan terhadap 100 responden di Kota Gorontalo diketahui pada umumnya responden berumur 21 - 29 tahun yaitu sebanyak 57 orang (57\%), umur 17
- 21 tahun yaitu sebanyak

Orang (24\%) dan sisanya $>35$ tahun yaitu sebanyak 8 orang $(8 \%)$. Hal ini terlihat pada tabel 1. Usia produktif antar 21 - 29 tahun berdasarkan laporan Ditjen PP \& PL Depkes RI Tahun 2007 merupakan kelompok umur yang paling banyak terjangkit viris HIV dan AIDS di Indonesia. Sehingga sangat penting untuk melakukan upaya penyuluhan kepda kelompok remaja pada usia produktif.

Sesuai dengan hasil penelitian di dapakan tingkat pendidkan responden masih rendah yaitu sejumlah 13 Orang (26\%) SD, dan 20 Orang (40\%) SMP. Hal ini dapat mempengaruhi pengetahuan responden karena semakin rendah tingkat pendidikan maka semakin rendah tingkat pemahamannya dan kemampuan untuk mengaplikasikannya lebih kecil.

Menurut Notoatmodjo (2003; 121) aplikasi dapat diartikan sebagai kemampuan untuk menggunakan materi yang telah dipelajari pada situasi atau kondisi yang sebenarnya. Selain itu terdapat juga responden yang berpendidikan SMU yaitu 17 
orang (34\%). Hal ini dapat mempengaruhi tingkat pengetahuan responden.

Namun, berdasarkan hasil penelitian ditemukan bahwa tidak selamanya tingkat pendidikan memberi pengaruh yang signifikan dalam pengetahuan responden. Hal ini terlihat pada tabel 3 dimana pengetahuan responden tentang alat KB adalah baik 47 Orang (94\%) dan cukup 3 Orang (6\%).

Hasil penelitian ini diperoleh bahwa pengetahuan Pekerja Seks Komersial (PSK) terhadap penyakit HIV/AIDS dari 162 responden diperoleh 96 orang (59.25\%) dikategorikan cukup, 38 orang (23.45\%) berpengetahuan baik dan 28 orang (17.30\%) diketahui berpengetahuan kurang.

Hal ini menunjukkan bahwa Pekerja Seks Komersial (PSK) yang berada di Kota Gorontalo SMA N 1 Amurang sebagian besar memiliki pengetahuan cukup tentang penyakit HIV/AIDS, pengertian, penularan dan pencegahan.

Menurut Notoatmodjo (2003) pengetahuan adalah hasil dari tahu dan ini terjadi setelah orang melakukan penginderaan terhadap suatu objek tertentu, penginderaan terjadi melalui panca indera manusia yakni indera penglihatan, penciuman, raba dan rasa. Apabila penerimaan perilaku baru atau adopsi perilaku melalui proses disadari oleh pengetahuan, kesadaran dalam sikap positif, maka perilaku tersebut akan bersifat langgeng. Sebaliknya apabila perilaku tersebut itu tidak disadari oleh pengetahuan dan kesadaran maka tidak akan berlangsung lama.

\section{Kesimpulan dan Saran}

Berdasarkan hasil penelitian dan pembahasan dapat ditarik kesimpulan Pengetahuan Pekerja Seks Komersial (PSK) tentang HIV/AIDS kategori baik 23,45 \%, Pengetahuan Pekerja Seks Komersial (PSK) tentang HIV/AIDS kategori cukup 59,25 \% dan Pengetahuan Pekerja Seks Komersial (PSK) HIV/AIDS kategori kurang 17,30\% Untuk meningkatkan pengetahuan Pekerja Seks Komersial (PSK) terhadap penyakit HIV/AIDS, maka diperlukan adanya informasi dan penyuluhan berkesinambungan 
oleh Puskesmas, guru-guru, tokoh agama baik secara individu maupun kelompok, melalui : kegiatan OSIS, kegiatan seminar yang dilaksanakan oleh petugas kesehatan bekerja sama dengan LSM.

\section{Ucapan Terima Kasih}

Ucapan terima kasih
disampaikan kepada tim
pengumpul data dan analsisi
data pada penelitian ini dan
Kepala Dinas Kesehatan
Provinsi Gorontalo.

\section{DAFTAR PUSTAKA}

Anonim. 2006. Data WHO. www.ihpcp.or.id

Dexa Media. No. 2 Vol. 9. 1996. Perilaku Sosial dan AIDS. Artikel. Jakarta

Durand, D.I. 2003. Karya Tulis Ilmiah. Akademi Kebidanan Poltekes Manado.

Departemen Kesehatan, Subdit IMS dan HIV/AIDS Pedoman Penatalaksanaan Infeksi Menular Seksual(IMS) dan HIV/AIDS Jakarta tahun 2005.

\begin{tabular}{llr} 
Dinas & \multicolumn{1}{c}{ Kesehatan } & Provinsi \\
& Gorontalo, & Buletin \\
& Epidemiologi disi & Kedua \\
Nopember 2006. & Gorontalo \\
Tahun 2006. &
\end{tabular}

George, R.K.A. 2006. Situasi HIV/AIDS Propinsi Sulawesi Utara Tahun 1997-Maret 2006.

Irwan SKM, 2006, Laporan Program P2 - HIV/AIDS Provinsi Gorontalo Tahun 2004 s/d 2006

Macfoedz, I. 2004. Statistik Deskriptif Dengan ContohContoh Kesehatan Masyarakat. Fitramaya. Jakarta

Mulyono, .B. 1998. Pendekatan Analisis Kenakalan Pekerja Seks Komersial (PSK) dan Penanggulangannya. Kanisius. Yogyakarta.

Notoatmodjo, S. 1997. Ilmu Kesehatan Masyarakat. Rineka Cipta. Jakarta.

____ 2003. Metodologi Penelitian Kesehatan. Rineka Cipta. Jakarta.

Padang. C.N. 2005. Karya Tulis Ilmiah. Akbid Poltekes Manado.

Panghalila, W. 1994. Seks Untuk Pekerja Seks Komersial (PSK). Orchid Yogyakarta.

Rahmat, K. 1994. Tantangan Pendidikan Tenaga Kesehatan. Pusat Pendidikan Tenaga Kesehatan. Jakarta.
Sinaya. 2004. 19 Pengidap HIV/AIDS di Gorontalo Meninggal. 
http://www.tempointeractive. com.201-04-05.

Sudijono, A. 2003. Pengantar Statistik Pendidikan. Raja Grafindo. Jakarta.

Tambajong F., 2003, Buku Petunjuk Penulisan Usulan Penelitian dan Karya Tulis Ilmiah, Politeknik Kesehatan Manado. 